\title{
Human Resource Orchestration for the Implementation of Entrepreneurial Opportunities
}

\section{Rinne $\mathrm{T}^{*}$}

Department of Management Studies, Aalto University School of Business, P.O. BOX 21230, 00076 AALTO, Finland

\begin{abstract}
Entrepreneurial service firms continuously seek new opportunities, trying to integrate identified opportunities as part of their service portfolio. Successful implementation of new opportunities requires effective management of human resources and development of competences required in these firms. The concept of resource orchestration offers a theoretical framework for strategic human resource management in entrepreneurial firms. However, there is limited research on how the firms orchestrate their human resources in the process of implementation of entrepreneurial opportunities. This paper is a case study of five small technology service firms. The paper examines how the case firms have managed and developed their human resources while implementing new business opportunities and how they have adopted the concept of resource orchestration. Results of this study show that the importance of different subprocesses of resource orchestration varies among small service firms and that often several sub-processes must be managed simultaneously. Successful implementation of new business opportunities requires good managerial abilities and is connected to the sub-processes of resource orchestration. Based on the findings of the study, this paper proposes a revised model for human resource orchestration for the process of entrepreneurial opportunity implementation.
\end{abstract}

Keywords: Management; Human resources; Resource orchestration; Strategic entrepreneurship; Service business

\section{Introduction}

Human resource management is an important part of strategic entrepreneurship (SE). Intangible resources, and specifically human resources, are the most important factor in creating competitive advantage for a firm [1]. Continuous opportunity seeking and exploitation processes are the core of SE, and all management activities related to entrepreneurial opportunities are critical for small firms. Human resource management in SE has been strongly based on Resource-Based View (RBV) [2, 3, 4]. In recent years, the concept of resource orchestration has contributed to SE by introducing an alternative approach to resource management [5]. Resource orchestration introduces the process of structuring, bundling, and leveraging resources in a firm $[5,6,7]$.

However, literature in the area of resource orchestration has had a strong theoretical approach, and only few empirical studies have been published in this field. Specifically, empirical research of resource orchestration in the context of implementing entrepreneurial opportunities is missing in this field. Additionally, earlier research [7, 8] argues that feedback loops exist among structuring, bundling and leveraging, and these phases do not necessarily follow each other in sequence. Also it is emphasized that the leaders need to synchronize their resource orchestration actions properly and that it is possible to implement different phases in different order. However, empirical research is missing on how the leaders synchronize their resource management actions in practice and how different phases and subprocesses of resource orchestration are implemented for opportunity implementation.

This paper aims to develop a deeper understanding of the resource orchestration concept by examining how human resources are managed during the process of opportunity implementation. We examine the challenges faced by small technology services firms over the life-cycle of opportunity implementation in those firms and link them with the resource orchestration process. In this paper, we also study what is the value of different phases in the resource orchestration process for small service firms and which phases and sub-processes these firms have implemented as well as how they have done it. In addition, we study how small service firms synchronize the different phases of resource orchestration process in their human resource management activities.

This paper is a case study of five small service firms and their activities in human resource management in the implementation of new entrepreneurial opportunities. Because this paper draws its theoretical background from SE, the focus of the research is specifically on the process of human resource management activities through the theoretical lens of the resource orchestration concept.

This paper provides several theoretical and managerial contributions. This study shows that, for opportunity implementation, some selected sub-processes of resource orchestration are more important than others and some sub-processes practically do not exist in the context of case firms. Sirmon et al. [8] suggest that the order of sub-processes is at least partly sequential. This study shows that sequential order for sub-processes is very limited and that most of the sub -processes must be managed simultaneously. It was also found that entrepreneurial leadership is an important part of the resource orchestration process and actions of entrepreneurial leaders are critical for successful opportunity implementation. Based on the findings of the study, this paper proposes a revised model for human resource orchestration in new opportunity implementation.

This paper is structured in the following way. The beginning of the paper discusses the theoretical background for this study. First, we review

*Corresponding author: Rinne T, Department of Management Studies, Aalto University School of Business, P.O. BOX 21230, 00076 AALTO, Finland, Tel: +358 407505 265; E-mail: timo.p.rinne@aalto.fi

Received November 06, 2014; Accepted April 21, 2015; Published April 30, 2015

Citation: Rinne T (2015) Human Resource Orchestration for the Implementation of Entrepreneurial Opportunities. J Entrepren Organiz Manag 4: 123 doi: 10.4172/2169-026X.1000123

Copyright: @ 2015 Rinne T. This is an open-access article distributed under the terms of the Creative Commons Attribution License, which permits unrestricted use, distribution, and reproduction in any medium, provided the original author and source are credited. 
the process of entrepreneurial opportunity implementation and then focus on human resource management from the perspective of SE, specifically on the concept of resource orchestration and its sub-processes. Theoretical background is followed by an introduction to research methodology, and major part of this paper reviews the results from the empirical part of the study. The paper is concluded with analysis of theoretical and managerial implications, and also limitations of the study.

\section{Theoretical Background}

In this paper, we analyze human resource processes and activities in case firms during implementation of new entrepreneurial opportunities. Several concepts and theories are developed for entrepreneurial opportunities, specifically for identification, recognition, discovery, and creation of opportunities [9, 10, 11]. If business potential of an opportunity is evaluated high enough, the next step in the process is implementation, i.e., exploitation of an opportunity. According to Buenstorf [12], the entrepreneur's subjective perception of an opportunity has an influence on the decision about how to pursue an opportunity. Also, the characteristics of organizations affect the management of opportunity exploitation and the evolution of the organization during this process [12].

Strategic planning and management is an important part of the process of opportunity implementation, for which a firm can choose different strategies. Strategic choices can be based for example on transaction costs, real options, market positioning, product diversification and usage of resources $[13,14]$, or superior competitive advantages, available market opportunities, and creation of business opportunities [8]. The need for integration of strategic management and entrepreneurship has been pointed out by several researchers [15]. One of the most recognized development in this field is strategic entrepreneurship (SE). SE is a process of simultaneous identification and exploitation of opportunities, which results in a firm's superior performance [2]. SE has theoretical roots in economics, international business, organization theory, sociology, and strategic management [15]. Strong integration between SE and a firm's strategy is evident, and $\mathrm{SE}$ is considered as a process of entrepreneurial activity with a strategic perspective [15]. Resource management is an important part of SE; 'Resources are managed strategically when their deployment facilitates the simultaneous and integrated use of opportunity- and advantage-seeking behaviors.' [2]. This definition summarizes the spirit of human resource management in SE; in parallel with the use of human resources in strategic projects and operations, resources are continuously used also for searching and implementing new business opportunities.

In the early days of SE, resource management was based on the theory of resource-based view, RBV $[2,4,16]$. In an RBV-based strategy, a firm creates competitive advantage by using and developing its unique resources, which are difficult to copy by competitors [17]. Resources can be tangible like financial capital, land, or machines, or intangible like human resources or social connections $[2,18]$. Intangible resources can create a unique resource position and competitive advantage more effectively than tangible resources, because intangible resources are often rare, tacit, and socially complex, and for this reason more difficult to copy $[15,18]$.

Teece and Shuen [19] have criticized RBV for not taking fully into account the influence of rapidly changing business environment. The concept of dynamic capabilities was introduced by them to complement resource management theories from the perspective of environment. Dynamic capabilities are managerial and organizational routines for reconfiguring and developing existing competences of a firm [20]. Development of dynamic capabilities has a strong link to a firm's strategy, because decisions about which resources the firm should further develop have an impact for the firm's future position $[19,21]$. The process of competence development and resource reconfiguration is intertwined with the firm's strategy process [22].

One of the latest developments in resource management is resource orchestration $[6,7,8]$, which is a process driven by the actions of managers. It integrates two concepts: resource management and asset orchestration. Resource management is the comprehensive process of structuring the firm's resource portfolio, bundling the resources to build capabilities, and leveraging those capabilities with the purpose of creating and maintaining value for customers and owners.' [8]. Asset orchestration is derived from the concept of dynamic capabilities, and it has two components: search/selection and configuration/deployment [6]. Integration between resource management and asset orchestration is known as resource orchestration $[6,8]$.

According to Sirmon et al $[6,8]$, the resource management framework includes three components; structuring, bundling, and leveraging resources. Each of these process components is further divided into three sub-processes. Structuring includes the sub-processes of acquisition, accumulation, and divestment. Firstly, resources in strategic markets must be identified, and the firm must make an investment to get some of those resources. Human resources can be acquired for example from competitors, customers, universities, or from open labor markets. After the acquisition, a resource portfolio for the firm is formed, and the acquired resources become a part of the strategic assets of the firm. Accumulation of resources requires actions for internal development. New employees can be trained to their duties through formal education or by making them to work together with other employees. Divestment of resources means continuous evaluation of the existing resources and figuring out how these resources could support the firm's strategy. Leaders need to evaluate whether unproductive resources could be reconfigured to support a new strategy and new objectives of the firm, or if the existing resources would need to be replaced by new resources to create a better match with the firm's future strategy. From human resource perspective, divestment includes training and relocation of personnel, or, for example in case of cost-cutting in an uncertain economic environment, also laying off a part of the unproductive human resources. Divestment must be planned very carefully so that it does not negatively affect the firm's competitive advantage[6,8].

Bundling resources has three sub-processes: stabilization, enrichment, and pioneering. During bundling, acquired resources are used to form new capabilities for the firm [8]. Stabilization aims to preserve the acquired resources and the competitive advantage of the firm. Continuous training is important in order to maintain the acquired competences. The purpose of enrichment is to extend the existing capabilities with new capabilities which are in line with the firm's existing strategy and operations. In the enrichment process, new resources with new competences are mixed with the existing capabilities of a firm. For example, a service firm can extend its value chain by making available services so far supplied by other firms. Another example of enrichment is to learn new competences and integrate these competences with existing capabilities. Pioneering means integration of completely new capabilities with existing capabilities. For identifying potential synergies of the firm's new capabilities, pioneering requires specific creativity and deep knowledge of the business field. According to Sirmon et al [8], when environmental uncertainty is high, the sub-processes of enrichment and pioneering are more likely to create competitive advantage and optimum value for customers than stabilization is $[6,8]$. 
The purpose of the leveraging process is to match internal resources with challenges from external business environment. The focus of the leveraging process is to use the firm's resources and capabilities for exploiting market opportunities and, in this way, create value to the customers. Leveraging includes the sub-processes of mobilization, coordination, and deployment of resources. These sub-processes have sequential links with each other. Firstly, resources must be mobilized before they can be coordinated and deployed. During mobilization, a firm tries to identify the resources needed for exploiting identified business opportunities. According to Sirmon et al. [8], during mobilization, the firm may plan its leveraging strategy, which requires particular capability configurations. A chosen strategy can be based on superior competitive advantages (resource advantage strategy), available market opportunities (market opportunity strategy), or creation of business opportunities (entrepreneurial strategy). Each strategic option involves different capability configurations, which are formed as a result of mobilization and coordination. The purpose of coordination is to integrate capabilities together to form required capability configurations. Effective coordination of capabilities requires creation of strong internal social capital in the firm. Social capital facilitates sharing of tacit knowledge and experience. Also, effective crossdivisional communication within the firm is needed to build social capital and to enable effective coordination of capabilities. Deployment is the final step in the leveraging process. Deployment means using the capabilities which were first mobilized and then integrated to the firm with the help of coordination. Deployment is the final step of implementation of the chosen leveraging strategy $[6,8]$.

Synchronization of resource management activities is particularly important in the leveraging phase [7]. Previously acquired and bundled resources need to be synchronized in order to create a performance advantage [23]. Need for synchronization is based on dependency between the phases and sub-processes. If a certain opportunity requires specific resources which first must be acquired, bundled and then leveraged, the processes will be dependent on each other, and a high level of synchronization is needed for using these resources efficiently [23]. High level of synchronization also results in a competitive advantage, because synchronization between the processes makes resource bundles more complex and more difficult to imitate by rivals $[8,23]$. However, not all resources need to be synchronized. If the processes are independent from each other, synchronization does not provide added value in the efficiency of resource deployment [23].

\section{Methodology}

The purpose of this study is to understand how the leaders of small service firms manage their human resources in the process of new business opportunity implementation. Empirical data was collected from five case studies and then analyzed. A multiple-case study method was chosen, because the use of multiple cases helps to improve constructive validity of the study and can result in a deeper understanding of the research problem $[24,25,26]$. Also, when using multiple-case studies and multiple realities, different standpoints are considered, which helps to avoid accepting too simple models or answers [27].

Because the purpose in this study is to understand the activities of people and social phenomena in organizations which they represent, an interpretive research approach was used. Interpretive approach offers a holistic view to social problems by close participation in the actors' realities and by interpretation of their experiences and perceptions [28]. The researcher also had an opportunity to observe activities in the case firms by attending meetings and in other situations during the process.
Observing is considered a useful research method: in interpretive research approach, the researcher may interact closely with the actors, which provides opportunities for deep insights into the research problems [25].

The case firms were selected from a field of business where the researcher had a good access to empirical data. A fairly specific business field was chosen: payment card services. Payment card services are normally provided through a technical infrastructure including IT servers and payment card personalization machines. In addition, the service process normally includes visual design of payment cards and planning of logistic processes for payment card distribution. Services include both standardized and configurable components.

Three criteria were used to select the case firms. Firstly, the number of employees in the firm should be small, fewer than 30 employees. Size of the firm is an important criterion, because in small firms resources are usually limited and all resources are in continuous use. Secondly, the firms must have endured in the market for more than two years. Strategic thinking is normally involved in a firm's operations once it has succeeded to stay alive the first years of its operations [29]. Thirdly, the firm must have implemented at least one new business opportunity which has created strategically important business operations in the firm. By using this set of criteria, it was possible to study strategic resource management in small service firms for the process of new business opportunity implementation.

Two primary sources of empirical data were used in this study. The first primary data source was face-to-face interviews of the managers in the case firms. Two persons from each case firm were interviewed, some of them more than once. In all case firms, the managing director and also either sales or operational director were interviewed. In most cases, the interviewees were also minority shareholders of their firms. Interviews were semi-structured and followed the themes identified from theoretical frameworks of strategic entrepreneurship and human resource management. The second primary source of data were observation memos from the researcher during participation in different meetings and other daily situations in the process of new opportunity implementation in the case firms. The secondary data sources included meeting memos and other confidential documents which were directly received from the firms. These documents complemented the findings from the primary data sources and supported the researcher's interpretation of the human resource processes in the case firms.

The interviews took place during 2012-13. All interviews were recorded and transcribed. Some details were checked with the interviewees after transcription in order to clear out possible misunderstandings. Data analysis was performed in parallel with data collection as an interactive process. Interactive process of collection and analysis of the data allows researchers to make adjustments to data collection methods if it is thought that the method requires changes to make the data more reliable, or its collection more efficient or more flexible [24].

Following the case-study approach by Eisenhardt [24], dataanalysis was performed in two phases. At first, the researcher got detailed knowledge of the case firms with a within-case analysis approach. All possible data was gathered from each case firm and the process of opportunity implementation was minutely studied. The second step was cross-case analysis, which was tightly coupled with the process of within-case analysis. In the cross-case analysis, the tactic was to classify data by their source (interviews, observation data, and secondary data like company documents) and in this way to identify 
similarities between the cases and their patterns. The purpose of this approach was to get to know well each case and its unique patterns and then to analyze the data through multiple diverse lenses. This approach makes a better fit between data and theory more likely, and also the likelihood of capturing novel findings from the data will increase [24].

\section{Findings}

Human resource management in small service firms is a complex process which requires managers to pay special attention to single individuals: their competences, capabilities, and individual needs. It is particularly challenging for a manager to develop human resources for implementing new entrepreneurial opportunities, while simultaneously using human resources for ongoing activities in business operations and customer projects.

The results of this study are summarized in Figure 1. By following the sub-processes of resource orchestration, resources can be managed successfully during opportunity implementation. Resource structuring, bundling, and leveraging each have their own particular role in the total process of human resource management. However, the results of this study show that different sub-processes are of different importance for the case firms, and some sub-processes are practically missing from the total process. In the structuring phase, only the subprocess of acquisition can be identified. Similarly, the bundling phase includes only the sub-process of enrichment. In the leveraging phase, the sub-processes of mobilization and coordination are intertwined and deployment is the most important sub-process. Three elements of managerial ability influence successful resource deployment: responsibility combined with trust, simultaneous management of subprocesses, and motivation of employees. Managerial ability influences all phases of resource orchestration, most importantly the leveraging phase. Details of the findings are discussed in the following chapters.

\section{Resources structuring}

Structuring includes the sub-processes of acquisition, accumulation and divestment. Among these three sub-processes, resource acquisition is the most important and critical activity for a firm [7]. For a small service firm, almost all employees are key people, playing important roles in a firm. These kinds of firms usually have limited budgets for resource acquisition. Due to small number of employees, each single person in the organization is a strategic resource, and each single person has a big influence to organizational activities in a firm.

All case firms used a similar approach in the selection process of new employees and prioritized personal characteristics and work experience ahead of formal education. Good communication skills, creativity, innovativeness, and personal self-responsibility were considered as key characteristics of a person. On the other hand, as payment card business is based on complex technologies, good understanding of these technologies was considered an important indicator of the related competence of that person. During acquisition, all case firms emphasized the importance of interviews in selection process. The case firms interviewed candidates several times before final selection. Referee statements were verified in all case firms, and all firms preferred to recruit persons known personally to them from the past whenever these kinds of people were available. People were hired from the open market and sometimes also from competitors. The managing director of Firm A commented on the importance of positive attitude:

"I think it is good to have technical background in this business. For marketing and commercial people, it is so hard to understand this business. It would be good to have people with a background in IT, electronics, and related areas. It is also important that the people have a strong will to learn new things themselves. It is very challenging to teach something in this business, so it is important that the people are willing to study themselves, too."

Accumulation of new human resources was not considered an important sub-process for the case firms. The main reason was lack of time for a long internal competence development process. At the startup stage, the most important thing for a firm was to hire people who could successfully perform their tasks without needing an education or training process. New employees were expected to be productive almost

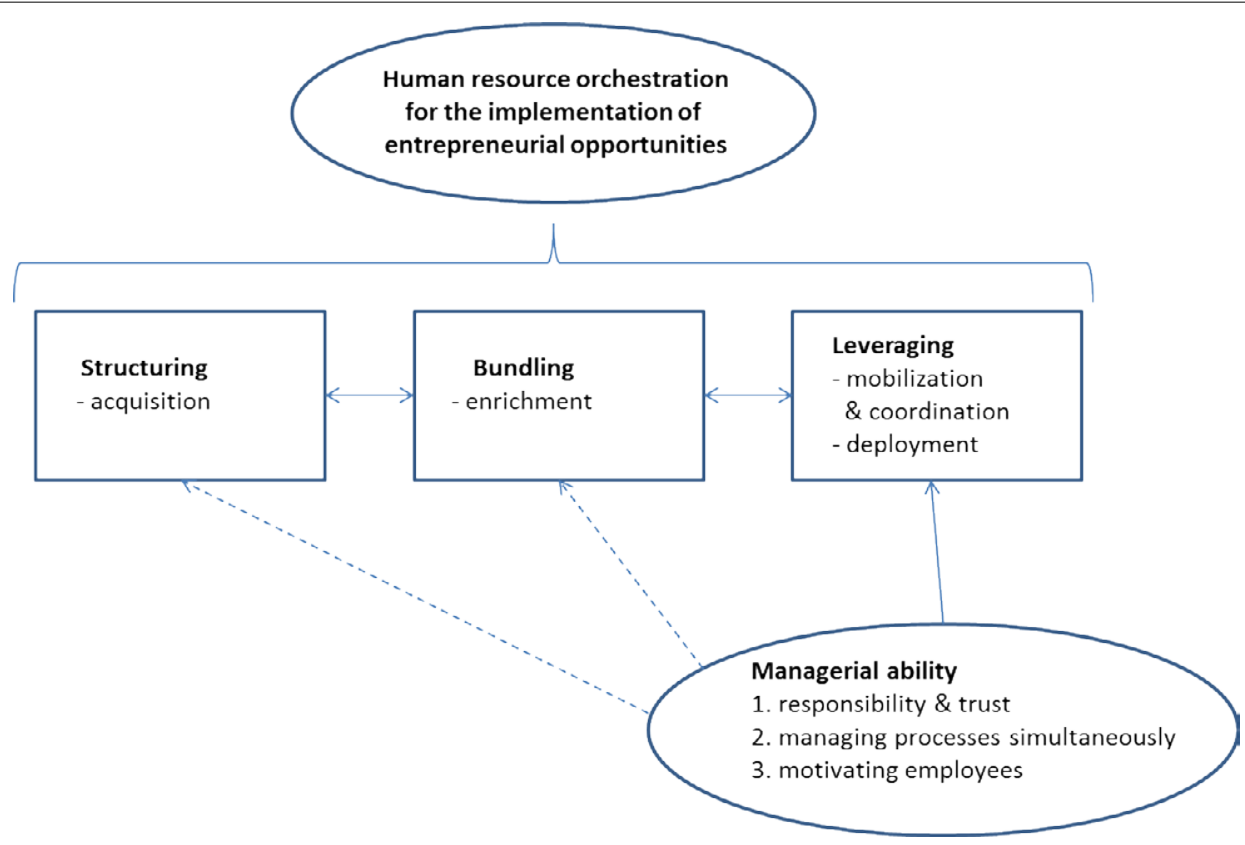

Figure 1: Human resource orchestration process in the implementation of entrepreneurial opportunities. 
immediately when they started to work for the firm. CTO of Firm B:

"When we want to hire an experienced person, we have to find a specific person who knows almost everything already. If you have enough time, you can educate and train a person for two years, maybe. But, if you need new resources right now, you have to hire someone who already can do the job."

\section{Managing director of Firm C adds:}

"Our activity is very, very specific. It is not normal for a generic IT manager to have the knowledge about our activity. If this is the case, then this person needs to have almost all knowledge already from the beginning and then to spend only a minimal time to learn the specific details."

However, all case firms recognized the importance and challenges of transferring tacit knowledge, and new employees started to work closely together with more experienced colleagues after joining the firm. All leaders in the case firms supported Hansen's [30] argument that transferring tacit knowledge is more efficient when experienced and inexperienced employees work together.

Divestment was not considered a critical phenomenon in the case firms either. Competences which were needed at the firm in the beginning were still needed and valid for the operations of current business activities. Therefore, employees did not change their tasks in these firms that frequently, and very few people had left their firm since they had joined it. The firms were continuously seeking for new opportunities, and they had also implemented some of them. The original business idea and operations were still important for the case firms, and the firm could deploy original resources for these activities.

Based on the findings from the case firms, the structuring process consists only from one sub-process, that of acquisition of resources. Acquired resources are expected to be productive immediately after acquisition, without a dedicated period for competence development after acquisition.

\section{Resources bundling}

Resourcebundling is closely connected to a firm's strategy process and opportunity implementation process. In strategically entrepreneurial firms, continuous seeking of opportunities is an important part of overall strategy. During resource bundling process, new and existing resources are developed in preparation for future challenges. Human resources need to have good education and knowledge of the business field, but they also need to learn new competences that are important for the implementation of new business opportunities.

Resource bundling includes the sub-processes of stabilization, enrichment and pioneering. As in the resource structuring process, there was only one sub-process which was considered important by the case firms. While enrichment was considered very critical, it was not possible to identify the sub-processes of stabilization and pioneering.

The case firms found enrichment to be a very critical sub-process for them. Leaders of the case firms actively collected information on new competences which were identified during the firms' strategy process. The case firms considered different types of training for developing new competences. They used academic education in universities, professional courses offered by training firms, knowledge transfer between partner firms, and self-learning. Academic education was considered to be an important source for basic knowledge of underlying technologies and for capabilities to understand new technologies. However, the case firms considered that internal training was the best option for competence development.

All case firms preferred either self-learning or knowledge transfer with partner firms. All case firms had close relationships with their partner firms in the same business field. Relationships between the firms had been established during joint sales activities and development projects. While offering services to big customers, the case firms felt that they are too small alone, and they decided to prepare joint offers with partners in order to be more competitive against big firms. The case firms had agreed to use an open dialogue and co-operation model with their partner firms in order to transfer knowledge from one firm to another. Both firms involved in the scheme named the contact persons who would be responsible for the process of knowledge transfer between the firms. If a firm decided to implement a new opportunity, it was possible for the other firm to involve their employees in the project in order to learn this new technology from the partner. Co-operation between the partners also included co-financed training sessions mainly for technical employees. CTO of Firm C says:

"External training is a bit tricky, because this kind of business is not taught anywhere. In this situation, we need to get help from our partners. As a result, we learn new technologies and we can store new information that we can replay later to new people. For example, some training sessions are recorded on video tapes. This is in order to guarantee that we can refresh some things later and to show the same to new persons."

As discussed, the sub-process of stabilization was missing from the case firms' resource orchestration process. The reason for the missing sub-process of stabilization was lack of time. All resources needed to be productive all the time, and there was no time for stabilization activities in the firms. Transfer and further development of existing competences was mostly based on co-operation between senior and junior colleagues, who worked together as pairs for long periods.

Also the sub-process of pioneering was missing in the case firms during opportunity implementation process. The main reason for neglecting pioneering was lack of time and resources. Small organizations in the case firms were continuously occupied by day-today operations and evaluation of new business opportunities, and they did not have R\&D type of teams or activities. It was not possible to allocate time for searching opportunities from different business fields which had little bearing with the case firm's strategy. For this reason, the leaders of the case firms did not actively develop employees and their competences for pioneering type of activities.

\section{Resources leveraging}

Once human resources and their competences are ready for new business opportunities, resources need to be leveraged, that is, mobilized, coordinated, and deployed. If the structuring and bundling processes are planned and implemented properly, it is fairly easy for a firm to exploit new opportunities from resource management perspective. However, it was found that many times the leveraging stage was achieved without proper completion of previous acquisition or bundling processes. This meant that a firm often faced new opportunities without having the necessary quantity of people or required competences. In this case, structuring and bundling processes would be very short and as effective as possible, and structuring and bundling would include only one subprocess in each of the main phases. In addition, especially the bundling process is often implemented partly in parallel with the leveraging process. 
In the case firms, the sub-processes of mobilization and coordination were intertwined with deployment. In small firms, it is normal that the same persons and teams contribute to the majority of the projects. In addition, from resource management perspective, the case firms did not experience any differences if the opportunity was based on different strategies: i.e., on superior competitive advantages, available market opportunities or business opportunities. Therefore, mobilization and coordination activities were needed mainly to verify the availability of the resources which already were being employed in other projects despite of a later strategic choice that had focused on a specific opportunity. In case of resource shortage, the managers needed to prioritize the projects and other activities where the same resources were needed. As a result, in some cases, selected tasks and projects were delayed due to prioritization, but most often it was possible to exceed the normal productivity rate of resources and handle all the tasks and projects in the agreed time schedule. Managing director of Firm D says:

"Some people in the company are able to stretch themselves, to work temporarily with $120-130 \%$ load for some time. This is the case if prioritization is not possible and there is more work to do than we have time. If I can get new resources, I use them to release others for the new project and put new people to existing tasks. In this way, I have more experienced people in the new projects, and new people are growing up with normal routine work, so they are capable of doing some other new things in the future. Then everybody is learning something new and everybody have positive pressures."

Deployment was identified as the most important sub-process during leveraging. Due to limited resources in small organizations, the leaders had a critical role in efficient deployment of resources. Holcomb et al. [23] argue that managerial ability is positively associated with resource productivity. Holcomb's main argument is that superior managers are able to add resource productivity specifically in situations where the quality of resources is low. When the quality of resources increases, positive influence of managerial ability for resources' productivity decreases. In other words, good managers are needed more when resources are not good; if resources are high in quality, managers are not needed that much.

\section{Managerial abilities}

The case firms recognized the importance of managerial ability in resource management. They identified managerial ability as a very important factor for resource orchestration in general and specifically for the leveraging phase. Three factors of managerial ability were found important for a successful leveraging process; 1) responsibility combined with trust, 2) management of overlapping processes, and 3) motivation of employees. These factors are explained more in detail in the following paragraphs.

All the leaders in the case firms strongly supported a leadership style where the responsibility of new opportunity implementation is given solely to one single person. The leaders argue that, if they put a single person in charge of implementation of a new business opportunity, it is easier for them to manage the development of that business case. Giving full responsibility for the implementation process requires a high level of trust from the manager towards the chosen employee. Traditional management models have favored different control mechanisms in order to monitor employees' performance [31]. These controls are often quantitative in nature, like detailed reporting or tracking of working hours. When the managers trust their employees, they do not need to monitor employees' performance by special controls made for that purpose. Spreitzer and Mishra [32] argue in their study that managers' trust towards their employees increases both individual and organizational performance. CTO in Firm D supports this approach:

"This is a good way. I think it is good to have freedom to do the things in my own way, but it is also very important to have the support available all the time, especially in the areas which are a bit outside of my core competence. I think responsibility for one person is better than to share the responsibility among a team."

No case firms had slack resources which could have been assigned for implementation of new opportunities. Also, the firms were suffering from the lack of required knowledge for opportunity implementation. Finally, all case firms needed, at the same time, to acquire more resources (acquisition), to develop new knowledge (bundling), and to implement new opportunities into profitable businesses (leveraging). Simultaneous management of the acquisition, bundling, and leveraging processes became a critical factor for the success of each project.

Despite of the resources having been fully allocated, all case firms were able to assign people for new opportunity implementation, even though these people needed to contribute considerably more time and efforts than their working agreements required them to do. This kind of working attitude requires high motivation. Entrepreneurial leaders have a key role in motivating employees in their duties [4,7,33]. Firstly, the leader must be able to communicate her vision to the other members of the organization to ensure that the activities of the employees are consistent with each other and with the firm's overall mission [34] Managing director of Firm E says:

"It requires strong motivation to work overtime for a long time, and from the manager's point of view, you need to make the target intellectually attractive, interesting and motivating for the people. Then people can get enthusiastic about the new opportunity, and they want to do their best."

Secondly, by showing and sharing his/her passion for new business opportunities, the leader can motivate employees to share the same goals and objectives, and with the same level of passion, as the leaders themselves [7]. Passion itself is a significant source of energy for entrepreneurs. In a context of entrepreneurship, passion is understood as love of work and love for the venture itself [35]. Communication between the leader and the employees has a key role in this process. By clearly communicating the vision about a new opportunity and about the importance of each person's role in the implementation process, passionate thinking and entrepreneurial behavior can be leveraged in an organization. Passionate feelings arise among people engaged in activities which relate to meaningful and salient self-identity [35]. Passion has a direct relationship to entrepreneurial behavior, including goal commitment, persistence, and creativity, and, through these factors, passion can increase entrepreneurial effectiveness [7,35].

\section{Conclusions}

This paper identifies several areas which can be used either to further support or further develop theoretical frameworks. Firstly, this paper supports the core elements of the resource orchestration concept by Sirmon et al $[6,8]$. It was found that the case firms manage their human resources in opportunity implementation by following the main phases of resource orchestration. However, it was found that all the sub-processes of research orchestration are not in place or their usage is very limited. In the structuring phase, only the acquisition subprocess could be identified, while the sub-processes of accumulation and divestment were not adopted at all by the case firms. Similarly, in the bundling phase, only the enrichment sub-process could be identified, while the sub-processes of stabilization and pioneering were 
not a part of human resource management processes in the case firms. In the leveraging phase, the deployment sub-process was considered to be the most important. The sub-processes of mobilization and coordination could not be identified separately in the case firms, but these were intertwined with each other with strong connection to deployment. The sub-processes of mobilization and coordination were more concerned with prioritization of tasks than with coordination of resources. All case firms recognized the importance of managerial abilities in resource synchronization. Responsibility combined with trust, simultaneous management of different phases and sub-processes of resource orchestration, and increasing employee motivation were found to be the most important characteristics of an entrepreneurial leader. These three elements helped the case firms to significantly increase productivity of human resources for the challenging projects in opportunity implementation.

Limitations of this study are mostly related to case study methodology and to the case firms themselves. The business field of the case firms, payment card services, is very narrow and specialized, there being only some hundreds of active firms globally in this business field. In addition, the business field is regulated and controlled by global payment card organizations, and therefore the access to the field is limited. Additionally, the selection of case firms was based on the researcher's personal access to those firms, and it was not possible to select the firms randomly.

As this study shows, there is need for further empirical research in the field of resource orchestration and strategic entrepreneurship in the future. Further empirical studies are needed to understand how the concept of resource orchestration is implemented in entrepreneurial opportunity implementation. Based on the results of this paper, it is likely that the contents of resource orchestration will differ between small and big firms, and also in different business fields. That said, empirical studies in other business fields are needed to develop the theoretical concept of resource orchestration further.

\section{References}

1. Hitt M, Bierman L, Uhlenbruck K, Shimizu K (2006) The Importance of resources in the Internationalization of Professional service firms: The good, the bad and the ugly. Academy of Management Journal 49: 1137-1157.

2. Ireland D, Hitt M, Sirmon D (2003) A model of strategic Entrepreneurship: The construct and its dimensions. Journal of Management 29: 963-989.

3. Kraus S, Kauranen I (2009) Conceptualizing a configuration approach based model of strategic entrepreneurship. International Journal of Strategic Management 9: 1-20.

4. Foss $\mathrm{N}$, Klein $\mathrm{P}$, Kor $\mathrm{Y}$, Mahoney J (2008) Entrepreneurship, subjectivism and the resource-based view: toward a new synthesis. Strategic Entrepreneurship Journal 2: 73-94

5. Barney J, Ketchen D, Wright M (2011) The Future of resource-based theory: revitalization or decline? Journal of Management 37: 1299-1315.

6. Sirmon D, Hitt M, Ireland R, Gilbert B (2011) Resource orchestration to create competitive advantage: breadth, depth, and life cycle effects. Journal of Management 37: 1390-1412.

7. Hitt M, Ireland R, Sirmon D, Trahms C (2011) Strategic entrepreneurship: creating value for individuals, organizations, and society. Academy of Management Perspectives 25: 57-75.

8. Sirmon D, Hitt M, Ireland R (2007) Managing firm resources in dynamic environments to create value: looking inside the black box. Academy of Management Review 32: 273-292

9. Ardichvili A, Cardozo R, Ray P (2003) A theory of entrepreneurial opportunity identification and development. Journal of Business Venturing 18: 105-123.

10. Sarasvathy S, Dew N, Velamuri R, Venkataraman S (2003) Three views of entrepreneurial opportunity. Handbook of Entrepreneur Research; An Interdisciplinary Survey and Introduction. Kluwer Academic Publishers.
11. Baron R (2006) Opportunity recognition as pattern recognition: How entrepreneurs "connect the dots" to identify new business opportunities. Academy of Management Perspective 20: 104-119.

12. Buenstorf G (2007) Creation and pursuit of entrepreneurial opportunities: An evolutionary economics perspective. Small Business Economics 28: 323-337.

13. Morris M, Schindehutte M, Allen J (2005) The entrepreneur's business model: toward a unified perspective. Journal of Business Research 58: 726-735.

14. Plummer L, Haynie J, Godesiabois J (2007) An essay on the origins of entrepreneurial opportunity. Small Business Economics 28: 363-379.

15. Hitt M, Ireland D, Camp M, Sexton D (2001) Entrepreneurial strategies for wealth creation. Strategic Management Journal 22: 479-491.

16. Kraus S, Kauranen I (2009) Strategic management and entrepreneurship: friends or foes? Int. Journal of Business Science and Applied Management 4: 37-50.

17. Wernerfelt B (1984) A resource-based view of the firm. Strategic Management Journal 5: 171-180.

18. Barney J (1991) Firm resources and sustained competitive advantage. Journa of Management 17: 99-120

19. Teece D, Shuen A (1997) Dynamic capabilities and strategic management. Strategic Management Journal 18: 509-533.

20. Eisenhardt K, Martin J (2000) Dynamic capabilities, what are they? Strategic Management Journal 21: 1105-1121.

21. Teece D (2007) Explicating dynamic capabilities: the nature and microfoundations of sustainable enterprise performance. Strategic Management Journal 28 1319-1350.

22. Borch O, Huse M, Senneseth K (1999) Resource configuration, competitive strategies, and corporate entrepreneurship: an empirical examination of small firms. Entrepreneurship Theory and Practice 24: 49-70.

23. Holcomb T, Holmes R, Connelly B (2009) Making the most of what you have: Managerial ability as a source of resource value creation. Strategic Management Journal 30: 457-485.

24. Eisenhardt K (1989) Building theories from case study research. Academy of Management Review 14: 532-550.

25. Diaz A (2009) Interpretive research aiming at theory building: adopting and adapting the case study design. The Qualitative Report 14: 42-60.

26. Piekkari R, Welch C, Paavilainen E (2009) The case study as disciplinary convention: evidence from international business journals. Organizational Research Methods 12: 567-589.

27. Perren L, Ram M (2004) Case-study method in small business and entrepreneurial research - mapping boundaries and perspectives. International Small Business Journal 22: 83-101.

28. Leich C, Hill F, Harrison R (2010) The philosophy and practice of interpretivis research in entrepreneurship: quality, validation and trust. Organizationa Research Methods 13: 67-84

29. Kuratko D, Audretsch D (2009) Strategic entrepreneurship: exploring different perspectives of an emerging concept. Entrepreneurship Theory and Practice 33. $1-17$.

30. Hansen M (1999) The search-transfer problem: the role of weak ties in sharing knowledge across organization sub-units. Administrative Science Quarterly 44 $82-111$.

31. Raelin J (2011) The end of managerial control? Group and Organization Management 36: 135-160.

32. Spreitzer G, Mishra A (1999) Giving up control without losing control: trust and its substitutes' effects on managers' involving employees in decision making. Group and Organization Management 24: 155-187.

33. Monsen P, Boss R (2009) The impact of strategic entrepreneurship inside the organization: examining job stress and employee retention. Entrepreneurship Theory and Practice 33: 71-104

34. Witt $U$ (1998) Imagination and leadership - the neglected dimension of an evolutionary theory of the firm. Journal of Economic Behavior and Organization 35: 161-177.

35. Cardon M, Wincent J, Singh J, Drnovsek M (2008) The nature experience of entrepreneurial passion. Academy of Management Review 34: 511-532. 